\title{
Revisiting the Tools for Innovation in Science Rodney Dietert and "Science Sifting"
}

\section{Ahmed Hamdy* \\ ahmed.pdf055@must.edu.eg}

\section{Abstract:}

When we go through libraries, searching for "scientific method", we usually have a long list of suggestions. The problem with the items in this list is that so many books take a descriptive approach as if the method is some kind of recipe.

Rodney Dietert, the author of "Science Sifting: Tools for Innovation in Science and Technology", draws our attention to the fact that when we use language, we not only communicate our thoughts and feelings to others, we also communicate and shape our reality.

Dietert refuses the common saying that states that "sticks and stones may break my bones but words can never hurt me,". Words cannot only harm us, they can lock us into mundane, mediocre thinking.

The author goes on to discuss what he dubbed the "problem of labels". Although defining ourselves and our activities is a common goal of using language in the same sense that we use physical symbols like specific clothes or

* Lecturer in Philosophy, Scientific Thinking Department at University Requirements Unit. 
business cards that identify our membership in a specific group, Dietert remarks that we usually use these labels in a way that tighten our space of activities.

Keywords: Science Sifting, Language of Science, Creativity in Science. 
When we go through libraries, searching for "scientific method", we usually have a long list of suggestions. The problem with the items in this list is that so many books take a descriptive approach as if the method is some kind of recipe.

Five years ago, or so, I have read a book that gives a different and creative perspective on the topic under the title of "Science Sifting: Tools for Innovation in Science and Technology", (World Scientific, 2013).

The author; Rodney Dietert is a Professor of Immunotoxicology at Cornell University, Ithaca, NY, USA, and author of the 2016 book: The Human Superorganism: How the Microbiome Is Revolutionizing the Pursuit of a Healthy Life from Dutton Penguin Random House. Rodney is in his 40th year at Cornell University faculty. He received his Ph.D. in immunogenetics from the University of Texas at Austin in 1977. Dietert has more than 300 publications, including 200 papers and book chapters, with the most concerning environmental risk factors, developmental immunotoxicity, and non-communicable diseases.

One of the most important goals of science is to describe the phenomenon under study. If a scientist was able to give a meticulous description of his phenomenon, he is so close to coming up with an explanation that defines the conditions under which the phenomenon occurs.

In chapter 6 and under the title "mind your language", Dietert draws our attention to the fact that when we use language, we not only communicate our thoughts and 
feelings to others, we also communicate and shape our own reality.

Dietert refuses the common saying that states that "sticks and stones may break my bones but words can never hurt me,". Words cannot only harm us, they can lock us into mundane, mediocre thinking.

In "Change Your Words, Change Your Life: Understanding the Power of Every Word You Speak", Joyce Meyer ${ }^{1}$ points out that we literally eat and digest our own words. You actually put frames for your abilities and your relationships through your words. Your internal self-talk can impact your level of joy, peace, and physical energy.

\footnotetext{
${ }^{1}$ Meyer, J., Change Your Words, Change Your Life: Understanding the Power of Every Word You Speak. Faith Words: New York, 2012.

Let's have a look at one of the most famous fallacies and see how can our words change our recognizing of reality;
} 
the false dilemma. It is also known as a false dichotomy or black and white fallacy. It means providing only two extreme positions when other options exist.

Examples:

- You're either with us or against us.

- $\quad$ Either a value always stands, or anything goes.

- $\quad$ Either Art is absolute or completely relative.

Alternatively, Dietert recommends us to choose words that describe an infinite array of potentials and possibilities. Dietert said:

"How you identify and describe your roadblocks and your ability to remove them is determined by the language you use.

Your training in descriptive precision may well box you into a corner at times. Roberta $\mathrm{Ness}^{2}$ emphasizes that the language you use reinforces your potential rigidity (your frames).

For example, how do you describe problems you encounter at work? The word-choice of "problem" with which you use to label a work issue already creates its own box. Meyer suggests a preferable way to characterize a roadblock is to call it a "situation" rather than a "problem." Situations tend to just be something to move beyond, whereas problems carry a yoke-like burden with them. Dr. Richard Bartlett ${ }^{3}$ goes further to suggest you are better served to call what we normally define as "problems" as just "stuff." Problems define and delineate hard boundaries whereas "stuff" is more like white noise. 
We know from personal experience that problems can loom as something huge and daunting, whereas stuff is often easily pushed aside. Stuff is just some fuzzy, immediate grouping of something. Stuff is much easier to rearrange into a more useful situation. You are less likely to label stuff as either good or bad. "Stuff" is the type of fuzzy language that provides you with greater wiggle room, which in turn helps you to see the path for moving beyond the roadblock". (Dietert, p.67)

The author goes on to discuss what he dubbed the "problem of labels". Although defining ourselves and our activities is a common goal of using language in the same sense that we use physical symbols like specific clothes or business cards that identify our membership in a specific group, Dietert remarks that we usually use these labels in a way that tighten our space of activities.

\footnotetext{
${ }^{2}$ Ness, R. B., Innovation Generation. Oxford University Press: Oxford, 2012.

${ }^{3}$ Bartlett, R., The Physics of Miracles. Atria Books: New York, 2009.

It goes without saying that we need to give a specific title for ourselves. "Sometimes you will have to label yourself in
} 
order to market your research expertise (e.g., I'm a geneticist) and progress within scientific circles." (Dietert, p.67)

"In fact, one of the first things that journals, publishers, granting agencies, large scientific societies, and even news media do is ask you to self-select your labels. This guides them in how they will interact with you per your grant proposal, manuscripts to review, chairing scientific sessions at conferences, and providing media comments on research findings." (Dietert, p.67)

Considering all these facts, Dietert draws attention to that labeling may confine our freedom and creativity.

Dietert cites Martha Beck ${ }^{4}$ who spoke about "the illusion of fixed conditions". Beck suggests that when we describe the facts of the world, we fall into the trap of assuming that these facts are truly permanent and rigidly fixed.

"She actually advocates refraining from using verbs of "being" when speaking of yourself, words like: is, are, am, was, has been, will be, hasn't, weren't, isn't, aren't, because these words identify your existence as something specific. For example, instead of saying "I am fat," which identifies you with your fat such that if you lost the fat, you would no longer exist, it's more preferable to say "I carry extra weight." If you carry something, you can always set it down without your existence is threatened." (Dietert, p.68)

The case of Dietert gives an evident example of this kind of labeling. His academic title provides the label of Professor of Immunotoxicology, identifying him as an Immunotoxicologist. This label usually excludes other 
activities of the author, like publishing in history and teaching creativity to researchers, and writing on this topic. Instead of using existential phrases like "I am ...", Dietert suggests using phrases like "I research immunotoxicology" and "I explore Scottish history," plus "I talk about creativity."

Dietert himself has a personal story to tell. In the 1990s, his research activities had changed so extensively that he petitioned to have his academic title changed. Of course, this is a rare case in academia and takes a considerable effort, but the lesson learned is that we should be careful, and make sure that when we give ourselves labels, we aren't making a ceiling that hinders our ability to creativity, especially as researchers.

\footnotetext{
${ }^{4}$ Beck, M., The Four Day Win. Rodale Press: Emmaus, PA, 2008.
} 